\title{
Experimental Measurement and Computational Simulation Analysis of Indoor Air Quality in Office-Integration of Voltage Adsorption Dust Collection Device and Energy Recovery Ventilator
}

\author{
Chih-Neng Hsu ${ }^{*}$ and Yun-Lin Tsai \\ Department of Refrigeration, Air Conditioning and Energy Engineering, National Chin-Yi University of \\ Technology, No. 57, Sec. 2, Zhongshan Rd., Taiping Dist., Taichung 41170, Taiwan, R.O.C.
}

(Received July 3, 2020; accepted November 7, 2020)

Keywords: energy recovery ventilator (ERV), indoor air quality (IAQ), particulate matters (PM), voltage adsorption dust collection device (VADCD)

The indoor air quality of a fully enclosed office can be improved by using an energy recovery ventilator (ERV) and a voltage adsorption dust collection device (VADCD). The effects of the indoor pollutant location and equipment setup on pollutants are analyzed by recording and observing the changes in indoor pollutant concentration, and by simulation using a computational fluid dynamics (CFD) approach. The experimental and simulation analysis results show that the $\mathrm{CO}_{2}$ concentration increases with the number of people indoors. The diffusion of $\mathrm{CO}_{2}$ can be gradually removed if an ERV is installed in an indoor room to recycle fresh air. Pollutants in the form of $\mathrm{PM}_{2.5} / \mathrm{PM}_{10}$ (particulate matter: $\mathrm{PM}$ ) suspended particles also enter the room as another pollution source when the ERV introduces external air into the room convection. At the same time, a VADCD can be installed in the room to absorb the indoor $\mathrm{PM}_{2.5} / \mathrm{PM}_{10}$ suspended particles and reduce their concentration to meet the standard specifications. The ERV and VADCD work together to improve the indoor air quality of fully enclosed offices and enhance the physical and mental health of office users.

\section{Introduction}

Because particulate matter (PM) has been discharged by combustion-fired power plants and by sandstorms in China, poor outdoor air quality has directly and indirectly affected Taiwan (R.O.C.) in recent years and, accordingly, poor air has permeated indoor spaces, reducing indoor air quality. Therefore, Executive Yuan of the Environmental Protection Administration issued the Indoor Air Quality Management Act ${ }^{(1)}$ on November 23, 2012, to improve indoor air quality and protect public health so that people can enjoy a healthier environment while indoors. Nowadays, most commercial buildings have replaced traditional windows with glass curtains or stone to decorate the outer walls of the buildings. However, the decoration causes the removal

*Corresponding author: e-mail: cnhsu@ncut.edu.tw https://doi.org/10.18494/SAM.2020.3143 
of windows adapted to introduce fresh outdoor air. When people work in indoor offices for a long period of time, $\mathrm{CO}_{2}$ and other pollutants may have a cumulative effect, leading to chronic poisoning. In addition, the American Society of Heating, Refrigeration, and Air-Conditioning Engineers suggested the minimum amount of fresh air for people working in different fields. ${ }^{(2,3)}$

Different countries in Asia stipulate different rules for indoor air quality because of factors such as latitudes and geographical locations. In Taiwan, the criteria related to pollutants specified in the Indoor Air Quality Management Act have been issued, and the management regulations for indoor air quality inspection ${ }^{(4)}$ have been published, which include regulations for periodic inspections ${ }^{(4)}$ and continuous monitoring. ${ }^{(4)}$ In China, ${ }^{(5)}$ the National Standard issued environmental indicators and limits for indoor air pollutants in public places. In Singapore, ${ }^{(6)}$ the concentration index of air pollutants has been proposed for commercial buildings. In South Korea, ${ }^{(7)}$ guidelines for air quality management in office premises have been produced. In Hong Kong, ${ }^{(8)}$ guidelines for the inspection of indoor air quality in offices and public places have been issued. In Japan, there are two references, namely, the indoor chemical concentration index ${ }^{(9)}$ and the Building Sanitation Management Standards, ${ }^{(10)}$ for indoor air quality pollutant index and standards. The air quality monitoring network of the Environmental Protection Administration, Taiwan, ${ }^{(11)}$ was established to monitor the outdoor air quality, whereby the daily air quality index (AQI) is obtained from the concentrations of $\mathrm{O}_{3}$, $\mathrm{PM}_{2.5}, \mathrm{PM}_{10}, \mathrm{CO}, \mathrm{SO}_{2}$, and $\mathrm{NO}_{2}$.

$\mathrm{CO}_{2}$ is a colorless and odorless gas ${ }^{(12)}$ in the earth's atmosphere with a concentration of about 350 to $500 \mathrm{ppm}$. Its concentration increases gradually in a closed space because of the respiration of people, and the increase in $\mathrm{CO}_{2}$ concentration may make people feel dizzy, vomit, feel excessive sleepiness, and even lose consciousness. Formaldehyde (HCHO) is a colorless gas and is generally used as a preservative in building materials, such as paint, furnishings, and coatings. This gas can be released slowly inside houses for up to ten years. HCHO increases the risk of cancers, such as nasopharyngeal carcinoma, and the production of leukocytes. ${ }^{(13)}$ The World Health Organization (WHO) ${ }^{(14)}$ classified HCHO as a Group 1 carcinogen. The $\mathrm{WHO}^{(14)}$ reported that the exposure of humans to polluted air containing $\mathrm{PM}_{2.5}$ or smaller particulates increases the incidence of cancers, cardiovascular diseases, respiratory diseases, and death. Particulates, namely, $\mathrm{PM}_{2.5}$ and $\mathrm{PM}_{10}{ }^{(15)}$ get into the blood system without being blocked by the human nasal cavity, pharynx, and larynx, causing pathological changes in the lungs and trachea and even cancers. Choi ${ }^{(16)}$ analyzed more than 10000 antepartum Korean women and found that the probability of premature birth increased many times upon exposure to an environment with an increased concentration of $\mathrm{PM}_{2.5}$. Shou et al. ${ }^{(17)}$ reported that $\mathrm{PM}_{2.5}$ particles cause pathological changes in the central nervous system, such as Alzheimer's disease, and can further enter the gastrointestinal tract, possibly causing gastrointestinal tract system disorders and central nervous system diseases. Yue et al. ${ }^{(18)}$ subjected mice to surgical operations to confirm that they had chronic left ventricular failure. When they were exposed to an experimental environment with $\mathrm{PM}_{2.5}$ and to an environment with purified air for three weeks, it was found that the short-term exposure to $\mathrm{PM}_{2.5}$ did not greatly affect the chronic left ventricular failure, whereas the exposure worsened their pulmonary vascular structure and pulmonary fibrosis. Accordingly, an environment polluted by $\mathrm{PM}_{2.5}$ has adverse effects 
on living organisms. Total volatile organic compounds (TVOCs) are odorous and pungent, ${ }^{(19)}$ and they cause symptoms such as immune system disorders, dizziness, and headaches, affect central nervous system functions, and even cause damage to the liver and hematopoietic system. Therefore, how to reduce the accumulation of these pollutants is an important issue. $\operatorname{Lin}^{(20)}$ used an energy recovery ventilator (ERV) and adjusted the positions of wind inlets and outlets. It was concluded that changing the positions where wind is introduced directly affected the $\mathrm{CO}_{2}$ concentration. Le ${ }^{(21)}$ used a needle discharge electrostatic precipitator to carry out indepth research and discuss the efficiency of collection. Lai ${ }^{(22)}$ used particle image velocimetry to study the tracks of charged particles in a two-stage electrostatic precipitator. In this study, we used a voltage adsorption dust collection device (VADCD) to replace the high-efficiency particulate air filter and cooperate with an ERV, thereby recording and observing the measured values of indoor pollutants. At the same time, we used computational fluid dynamics (CFD) to simulate the distribution of the pollution. We found that the indoor air quality in an office can be improved to attain environmental quality improvement and reduce the energy consumption. A flow chart of this study is shown in Fig. 1.

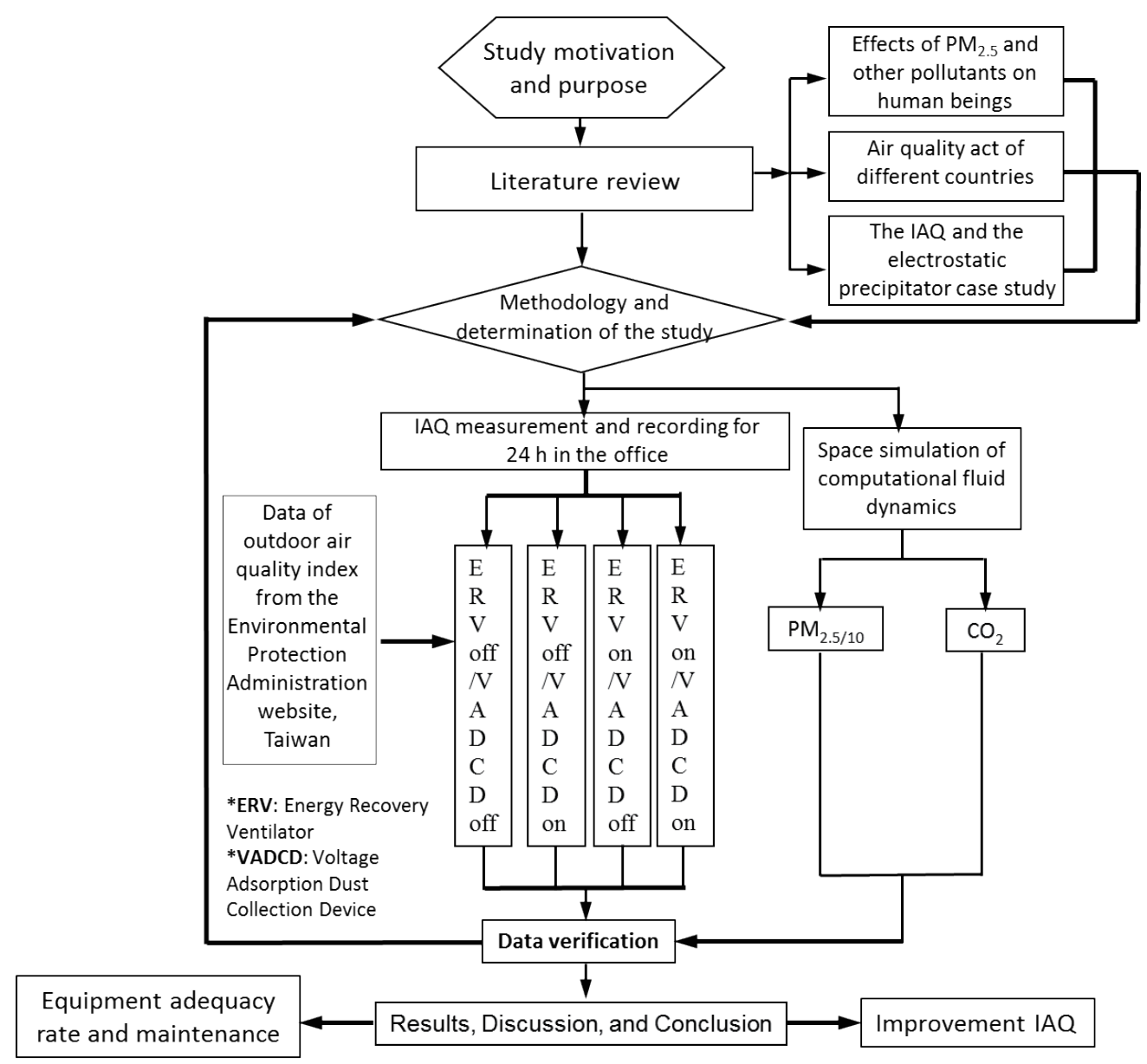

Fig. 1. Flow chart of this study. 


\section{Computational Theoretical Equation}

CFD can use computational programming languages. The motion diagrams of CFD can be generated by visualization, and the computation of solutions should comply with the law of conservation of mass, the law of conservation of energy, and the law of conservation of momentum. By using the technology of grid generation and setting the initial and boundary conditions appropriately, a valid result can be achieved after the convergence of the computation.

\subsection{Basic assumptions of numerical simulation}

To simplify the computation of the simulation, the following settings are adopted:

1. The fluid in the space is an ideal gas in an incompressible flow field.

2. The effect of gravitation is considered.

3. The flow field is subjected to a transient analysis using a standard $k-\varepsilon$ turbulence model.

4. The walls are assumed to be insulating, regardless of the roughness of the wall surface.

5. Three-dimensional rectangular coordinates are used.

6. The target is set as the wall surface.

\subsection{Finite volume method (FVM)}

The FVM is a control volume method. This method divides a computational area into continuous and unrepeatable control volumes, and uses integral calculus to calculate the surface flux of each control volume and subject the volume to mathematical discretization.

\subsection{Semi-implicit method for pressure-linked equations (SIMPLE) method}

The SIMPLE method was developed by Patankar and Spalding, ${ }^{(23)}$ and Patankar ${ }^{(24)}$ as a method of calculating the compressible and incompressible flow fields. The basic concept of the SIMPLE method is that after a pressure field is determined, a solution to the momentum equation after mathematical discretization is obtained to determine the velocity field. In this simulation, the adopted governing equation is divided into a continuity equation, a momentum equation, and an energy equation.

1. Continuity equation

$$
\frac{\partial \rho}{\partial t}+\frac{\partial(\rho u)}{\partial x}+\frac{\partial(\rho v)}{\partial y}+\frac{\partial(\rho w)}{\partial z}=0
$$

2. Momentum equation

$$
\frac{\partial \rho u}{\partial t}+u \frac{\partial \rho u}{\partial x}+v \frac{\partial \rho u}{\partial y}+w \frac{\partial \rho u}{\partial z}=-\frac{\partial \vec{P}}{\partial x}+\rho \vec{g}_{x}+\mu\left[\frac{\partial^{2} u}{\partial x^{2}}+\frac{\partial^{2} u}{\partial y^{2}}+\frac{\partial^{2} u}{\partial z^{2}}\right]
$$




$$
\begin{gathered}
\frac{\partial \rho v}{\partial t}+u \frac{\partial \rho v}{\partial x}+v \frac{\partial \rho v}{\partial y}+w \frac{\partial \rho v}{\partial z}=-\frac{\partial \vec{P}}{\partial y}+\rho \vec{g}_{y}+\mu\left[\frac{\partial^{2} v}{\partial x^{2}}+\frac{\partial^{2} v}{\partial y^{2}}+\frac{\partial^{2} v}{\partial z^{2}}\right] \\
\frac{\partial \rho w}{\partial t}+u \frac{\partial \rho w}{\partial x}+v \frac{\partial \rho \mathrm{w}}{\partial y}+w \frac{\partial \rho w}{\partial z}=-\frac{\partial \vec{P}}{\partial z}+\rho \vec{g}_{z}+\mu\left[\frac{\partial^{2} w}{\partial x^{2}}+\frac{\partial^{2} w}{\partial y^{2}}+\frac{\partial^{2} w}{\partial z^{2}}\right]
\end{gathered}
$$

3. Energy equation

$$
\frac{\partial(\rho T)}{\partial t}+d(\rho v T)=d\left(\frac{k}{C_{p}} \nabla T\right)+\frac{S_{T}}{C_{P}}
$$

4. $k$ - $\varepsilon$ turbulence model

The turbulence kinetic energy $k$ satisfies the equation

$$
\frac{\partial(\rho k)}{\partial t}+\frac{\partial\left(\rho U_{j} k\right)}{\partial x_{j}}=\frac{\partial}{\partial x_{j}}\left[\left(\mu+\frac{\mu_{l}}{\sigma_{k}}\right) \frac{\partial k}{\partial x_{j}}\right]+R_{i j} \frac{\partial U_{i}}{\partial x_{j}}-\rho \varepsilon
$$

the dissipation rate $\varepsilon$ of the turbulence kinetic energy satisfies

$$
\frac{\partial(\rho \varepsilon)}{\partial t}+\frac{\partial\left(\rho U_{j} \varepsilon\right)}{\partial x_{j}}=\frac{\partial}{\partial x_{j}}\left[\left(\mu_{l}+\frac{\mu_{t}}{\sigma_{\varepsilon}}\right) \frac{\partial \varepsilon}{\partial x_{j}}\right]+C_{\varepsilon 1} \frac{\varepsilon}{k}\left(\bar{R}_{i j} \frac{\partial U_{i}}{\partial x_{j}}\right)-C_{\varepsilon 2} \rho \frac{\varepsilon^{2}}{k}+C_{\varepsilon 3} \rho \varepsilon \frac{\partial U_{i}}{\partial x_{j}}
$$

and the Reynolds stresses in the $k-\varepsilon$ equation are given by

$$
\bar{R}_{i j}=-\overline{\rho u_{i} u_{i j}}=-\frac{2}{3} \rho k \delta_{i j}+\mu_{t}\left(\frac{\partial U_{i}}{\partial x_{j}}+\frac{\partial U_{j}}{\partial x_{i}}\right)=-\frac{2}{3} \rho k \delta_{i j}+2 u_{t} S_{i j}
$$

where $k=0.419, C_{\mu}=0.09, \sigma_{k}=1.0, \sigma_{\varepsilon}=1.22, \sigma_{\varepsilon 1}=0.09, \sigma_{\varepsilon 2}=1.92$, and $\sigma_{\varepsilon 3}=-0.33$.

5. Equation of the concentration diffusion

$$
\frac{\partial(\rho m)}{\partial t}+d(\rho v m)-d\left(D_{1} g r a d m_{1}\right)=S
$$

where $D_{1}$ is the diffusion coefficient, $\rho v m$ is the flow density of the concentration convection, $S$ is the formation rate of the concentration per unit volume, and $D_{1}$ gradm $_{1}$ is an expression taken from Fick's law. 
6. Discrete phase model (DPM)-equation of particle motion and boundary

We have used the equation of the DMP method to solve the behavior modes of particle motion and particle boundary collision (Fig. 2). The equations listed below are used in the calculation methods.

$$
\frac{d\left(\vec{v}_{p}\right)}{d t}=\frac{1}{m_{p}} \vec{F}_{p}=\frac{1}{m_{p}}\left(\vec{F}_{\text {drag }}+\vec{F}_{\text {pressure }}+\vec{F}_{\text {gravitation }}\right)
$$

$m_{p}=$ mass of particle

$\vec{F}_{p}=$ net force added to particle

$\vec{F}_{\text {drag }}=$ resistance subjected by particle

$\vec{F}_{\text {pressure }}=$ flow pressure of particle

$\vec{F}_{\text {gravitation }}=$ gravity acting on particle

\section{Computational Model}

The office where this study is carried out is measured and defined as an analytic model of a simulated site. Then, it is also used as an experimental verification site. The model is $1500 \mathrm{~cm}$ in length, $710 \mathrm{~cm}$ in width, and $260 \mathrm{~cm}$ in height. Six sets of office desks and chairs are arranged with a partition separating each person from another person to simulate an actual office environment as shown in Figs. 3 and 4. The grid is an important part of the CFD simulation. The details of the grid such as the density, the quality, and the number of grids can affect the result of the simulation. The shapes of a grid can be two-dimensional quadrilaterals, triangles, hexahedra, rhombi, polyhedral, and three-dimensional tetrahedral. In the simulation, there are 3037344 grids, the maximum slope is 0.87 , and a hexahedron grid is adopted, as shown in Fig. 5. Numerical simulation and modeling analysis must set the boundary and initial conditions as computational parameters, including the pollutant concentration, the ERV, the

Particle escapes from the boundary

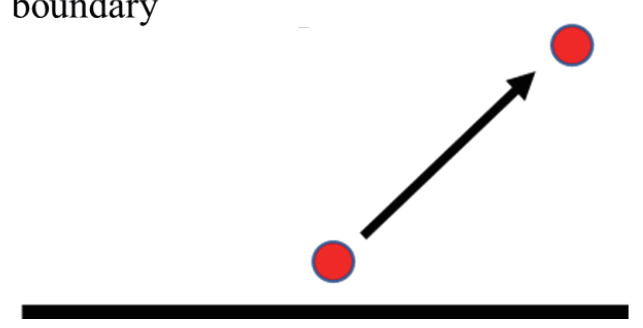

Particle is caught by the boundary

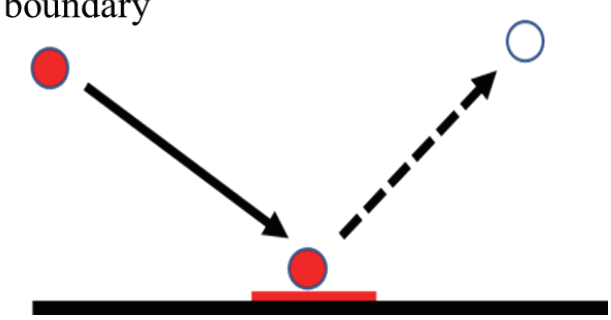

Fig. 2. (Color online) Relationship between motion of particle and boundary. 


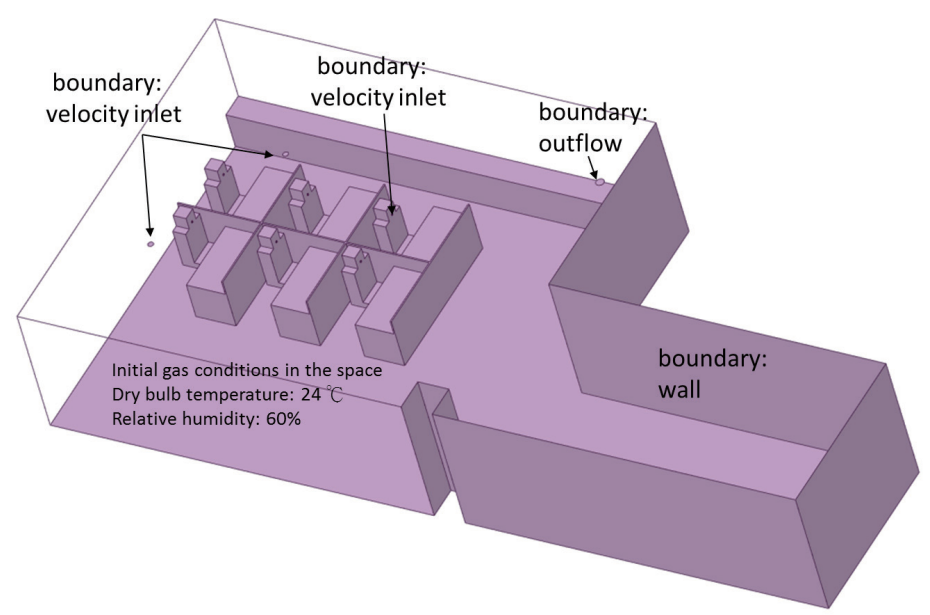

Fig. 3. (Color online) Model of enclosed office. Rectangular parts represent office staff with a square mouth with dimensions of $3 \times 3 \mathrm{~cm}^{2}$.

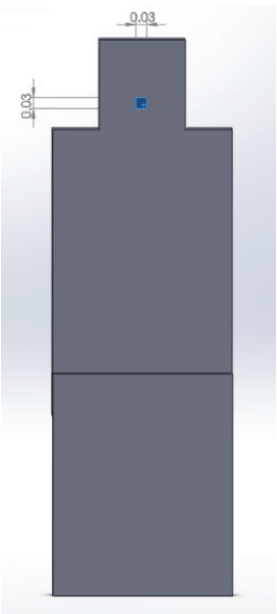

Fig. 4. (Color online) Model of office staff.

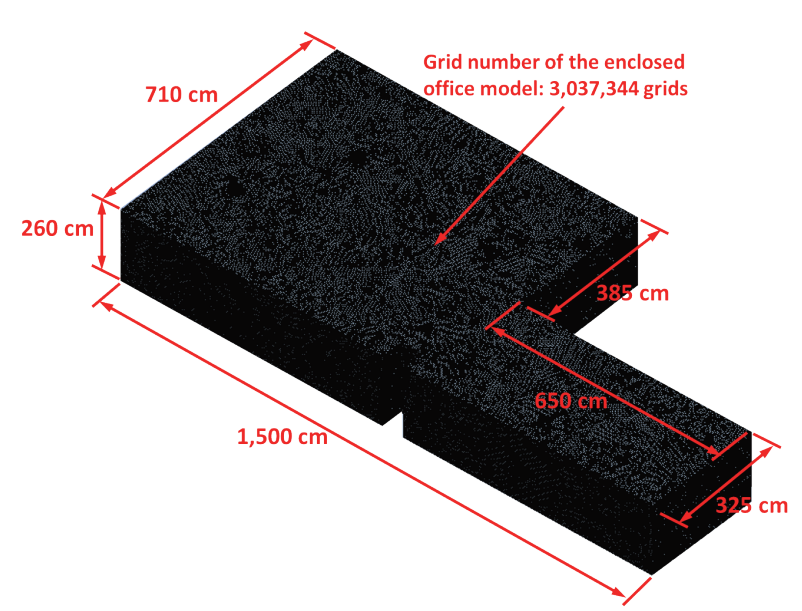

Fig. 5. (Color online) Grid number of enclosed office model: 3037344 grids.

VADCD, the initial setting of environment, the $\mathrm{CO}_{2}$ breathed out by people, the wind outlet of the ERV, the wind inlet of the ERV outflow, and the wall boundary, as shown in Table 1.

\section{Results and Discussion: Computational Simulation Analysis}

\subsection{Simulation result for natural convection indoors}

Figure 6 shows the result for natural convection, where $\mathrm{CO}_{2}$ produced by six office staff accumulated for $8 \mathrm{~h}$ in an environment without any outdoor air and without using air conditioning. The $\mathrm{CO}_{2}$ concentration in the main office area reached $1530 \mathrm{ppm}$ and that at 
Table 1

Simulation and settings of concentration in space containing $\mathrm{CO}_{2}, \mathrm{PM}_{2.5}$, and $\mathrm{PM}_{10}$ by using ERV and VADCD.

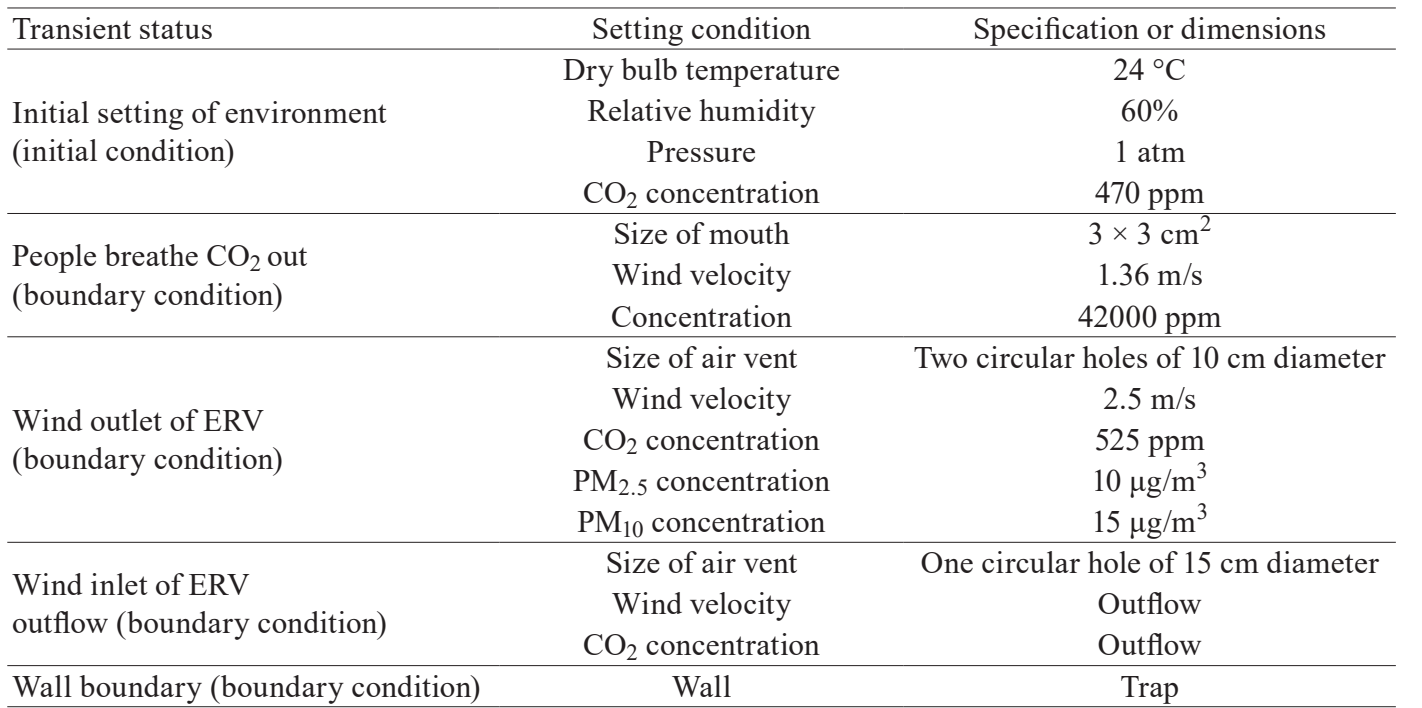

Note: By changing the concentrations of $\mathrm{PM}_{2.5}$ and $\mathrm{PM}_{10}$ at the wind outlet, it is possible to analyze and simulate the statuses of $\mathrm{PM}_{2.5}$ and $\mathrm{PM}_{10}$ subjected to filtering by the VADCD.
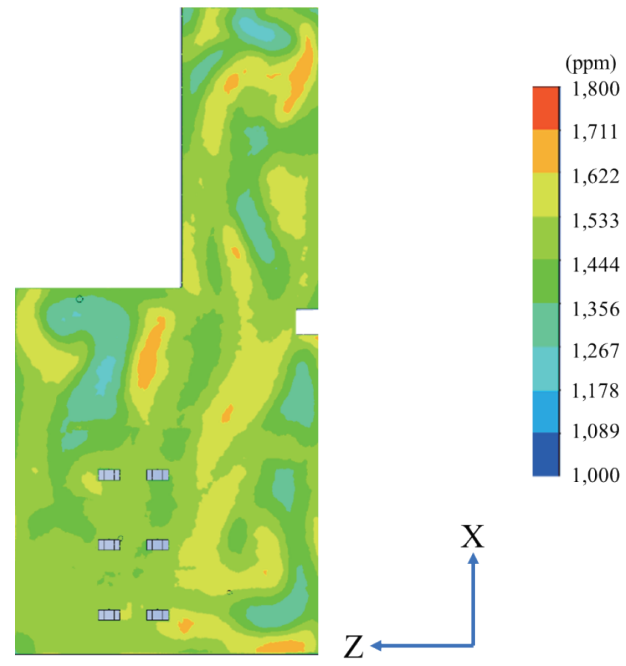

Fig. 6. (Color online) $X-Z$ plan view showing concentration field of $\mathrm{CO}_{2}$ for natural indoor convection.

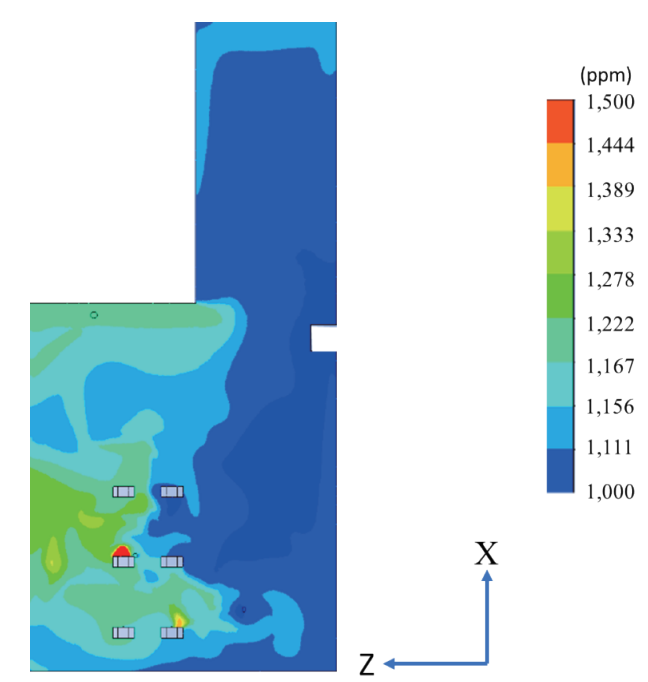

Fig. 7. (Color online) $X-Z$ plan view showing concentration field of $\mathrm{CO}_{2}$ under operation of ERV.

other points reached $1700 \mathrm{ppm}$. In this simulation, the average concentration in the whole office reached $1600 \mathrm{ppm}$ after $8 \mathrm{~h}$ in the enclosed office space with an area of $81.5 \mathrm{~m}^{2}$.

\subsection{Simulation with ERV in open state}

Figure 7 shows that the highest $\mathrm{CO}_{2}$ concentration was observed around the seats of the staff in the space. Because the ERV induced convection, a walkway without touching the wind 
outlets can have a lower $\mathrm{CO}_{2}$ concentration, preventing the diffusion of $\mathrm{CO}_{2}$ away from the seats of the staff.

\subsection{Concentration field of $\mathrm{PM}_{2.5}$ in $X-Z$ direction when operating both $\mathrm{ERV}$ and VADCD}

Figure 8 shows the result obtained when outdoor fresh air was introduced by the ERV and the polluted indoor environment was subjected to filtering by the VADCD when the $\mathrm{PM}_{2.5}$ concentration in the introduced outdoor air reached $40 \mu \mathrm{g} / \mathrm{m}^{3}$. The pollutants diffused around the wind inlets and accumulated in corners of the ceiling; this area did not have air flow of the wind outlets and inlets. The seat area of the office staff is less than $10 \mu \mathrm{g} / \mathrm{m}^{3}$, so there is less pollution caused by $\mathrm{PM}_{2.5}$.

\subsection{Concentration field of $\mathrm{PM}_{10}$ in $X-Z$ direction when operating both $\mathrm{ERV}$ and VADCD}

Figure 9 shows that when the particulate $\mathrm{PM}_{10}$ subjected to filtering was introduced into the office, $\mathrm{PM}_{10}$ reduced the cumulative number of many pollution sources, although they suspended on the ceiling, and the $\mathrm{PM}_{10}$ concentration around the office staff decreased to $20 \mu \mathrm{g} / \mathrm{m}^{3}$. Therefore, a notable improvement in the environment was attained.

\subsection{Analysis of simulation results for different positions of wind inlets and outlets}

The $\mathrm{CO}_{2}$ concentration was simulated by $\mathrm{CFD}$. By comparing the conditions of natural convection with those of mandatory convection induced by the ERV, the highest daily $\mathrm{CO}_{2}$ concentration among the measured points of the simulated office decreased by $27 \%$, from 1600 to $1167 \mathrm{ppm}$, when the ERV was used. Therefore, the introduction of outdoor fresh air
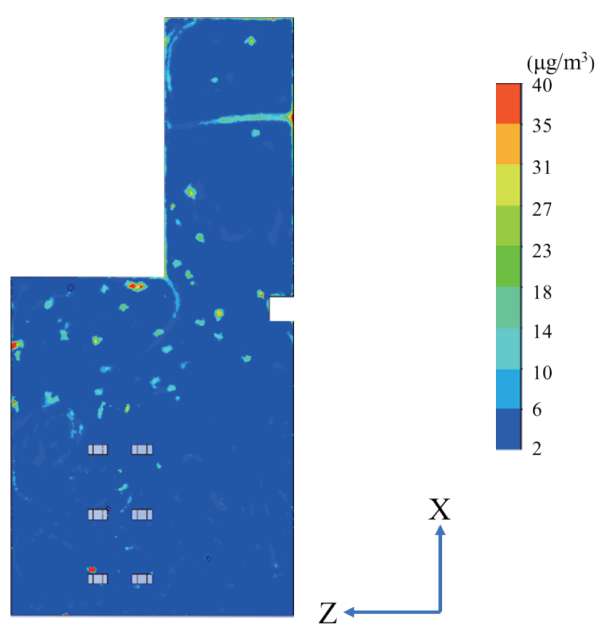

Fig. 8. (Color online) Concentration field of $\mathrm{PM}_{2.5}$ in $X-Z$ direction under operation of both ERV and VADCD.
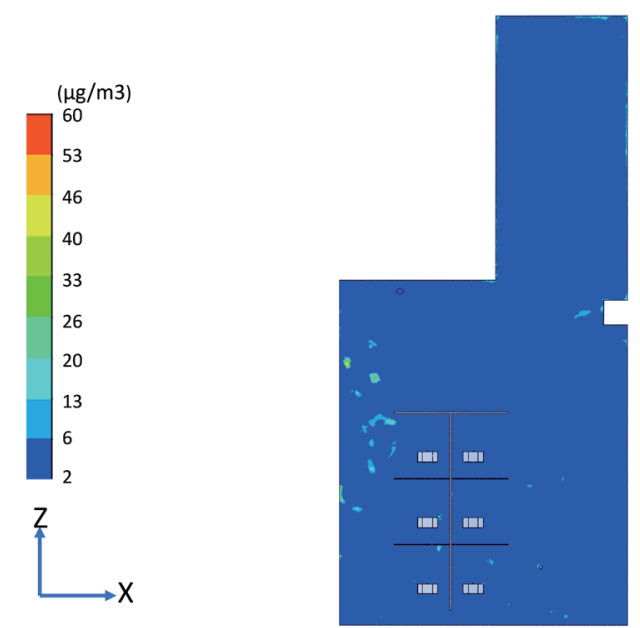

Fig. 9. (Color online) Concentration field of $\mathrm{PM}_{10}$ in $X-Z$ direction under operating of both ERV and VADCD. 
can efficiently reduce the $\mathrm{CO}_{2}$ concentration in a polluted indoor space. However, all the experiments and simulations employed a ventilation frequency of 0.7 times per hour, which is insufficient to meet the needs of offices. Therefore, we suggest that an enclosed office design should introduce fresh air to indoor convection air-circulation to prevent and reduce $\mathrm{CO}_{2}$ concentration and take into account external guests or visitors to ensure high air quality. When the $\mathrm{PM}_{2.5}$ concentration was simulated by CFD, it was observed that when a high concentration of unfiltered $\mathrm{PM}_{2.5}$ particles was introduced into the office, the particles accumulated in dead corners inside the building but diffused within the main working area. The introduction of indoor fresh air reduced the concentration of $\mathrm{PM}_{2.5}$ after filtering. In the simulation, indoor particulates moved gradually to the wind inlets to improve the air quality of the working space, but the air quality of the indoor space where $\mathrm{PM}_{2.5}$ remained did not improve. Accordingly, it can be inferred that increasing the amount of ventilation can reduce the $\mathrm{PM}_{2.5}$ concentration after filtering. As shown from the simulation result in Fig. 10, the $\mathrm{CO}_{2}$ concentration differed with the outlet position. When the positions of the air vents were all turned toward the working area of the staff, the $\mathrm{CO}_{2}$ concentration in the working area decreased by $5 \%$, but there was an increase in the concentration in the unoccupied walkway. Figure 11 shows the simulated distribution of $\mathrm{PM}_{2.5}$ in the interior of the office for different positions of the air vent with the ERV and VADCD on. When a high concentration of outdoor $\mathrm{PM}_{2.5}$ particles that had been filtered entered the office, the particles diffused within the walkway situated in the lower right corner and accumulated on the upper right wall. However, there is a notable reduction in the concentration of the diffused $\mathrm{PM}_{2.5}$. Figure 12 shows the simulated distribution of $\mathrm{PM}_{10}$ inside the office for different positions of the air vent with the ERV and VADCD on. When high-concentration outdoor $\mathrm{PM}_{10}$ particles were filtered and entered the office, they became concentrated within the walkway situated in the lower right corner.

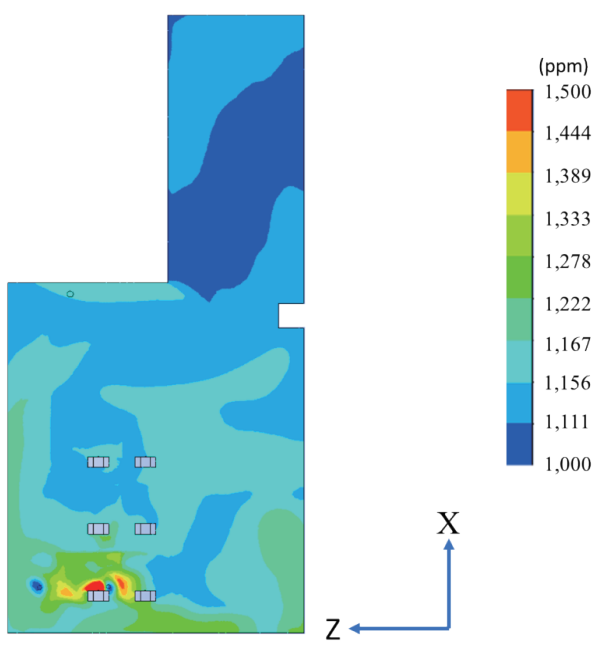

Fig. 10. (Color online) Numerical simulation of $\mathrm{CO}_{2}$ concentration at different vent positions.

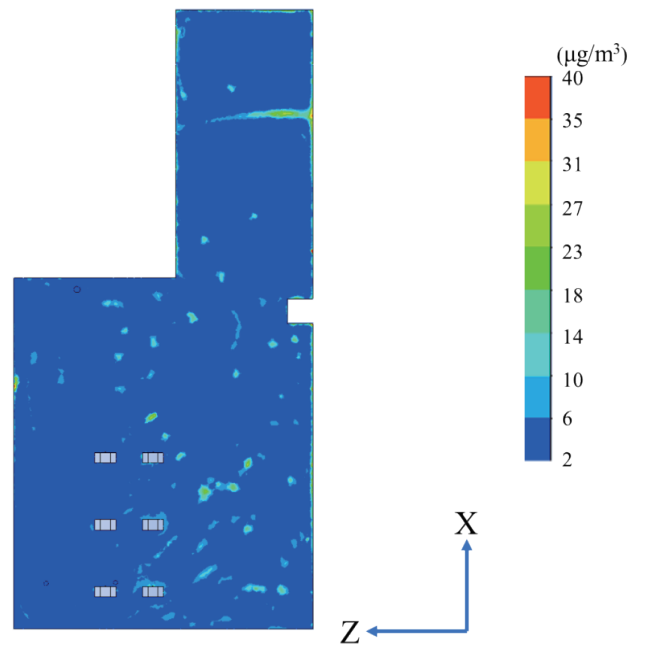

Fig. 11. (Color online) Concentration field of $\mathrm{PM}_{2.5}$ at different vent positions when ERV and VADCD are in operation. 


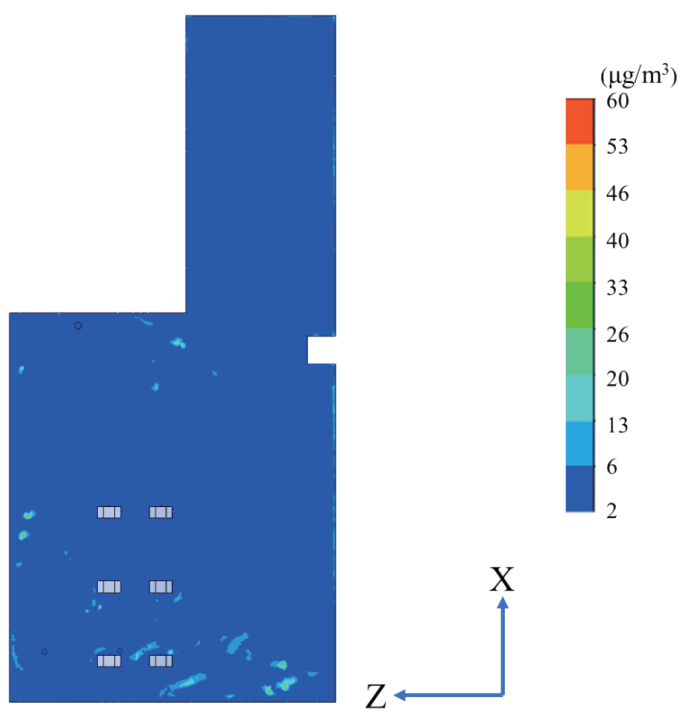

Fig. 12. (Color online) Concentration field of $\mathrm{PM}_{10}$ at different vent positions when ERV and VADCD are in operation.

\section{Experimental Approach}

\subsection{Introduction to experiments}

The following data about the air quality of the office are recorded: $\mathrm{CO}_{2}$, carbon monoxide (CO), $\mathrm{HCHO}$, TVOCs, $\mathrm{PM}_{2.5}, \mathrm{PM}_{10}$, dry bulb temperature, and relative humidity. The indoor air quality is measured to record the changes in the values of pollutants and, at the same time, the ERV and VADCD operation statuses are considered. The monitoring and recording frequencies of the apparatus for the sources of indoor air quality pollution are continuously recorded on a database all day long for the analysis and interpretation of measurement data.

\subsection{Experimental equipment}

\section{A. VADCD}

The VADCD shown in Figs. 13 and 14 includes an insect-proof filter at the front end to filter larger outdoor pollutants, such as insects and visible dust. Fine dust is mainly filtered by passing an air flow through a dust-collecting board disposed in the core of the device. The operating principle of the core is that electric filaments using the principle of corona discharge give fine particles, namely, $\mathrm{PM}_{2.5} / \mathrm{PM}_{10}$ to carry positive charges, which then flow into the dust-collecting board. The dust-collecting board comprises multiple metal boards placed in a certain arrangement. One side of each metal board is a positive pole and the other side is a negative pole. Because opposite poles attract each other and positive poles repel each other, the flowing fine particles with positive charges are adsorbed to purify air. A single-phase $220 \mathrm{~V} / 60 \mathrm{~Hz}$ power source is used, the air volume is $150 \mathrm{CMH}$, the power consumption is $12 \mathrm{~W}$, the efficiency of dust collection and adsorption is above $95 \%$, and the loss of static pressure is $20.5 \mathrm{~Pa}$. 


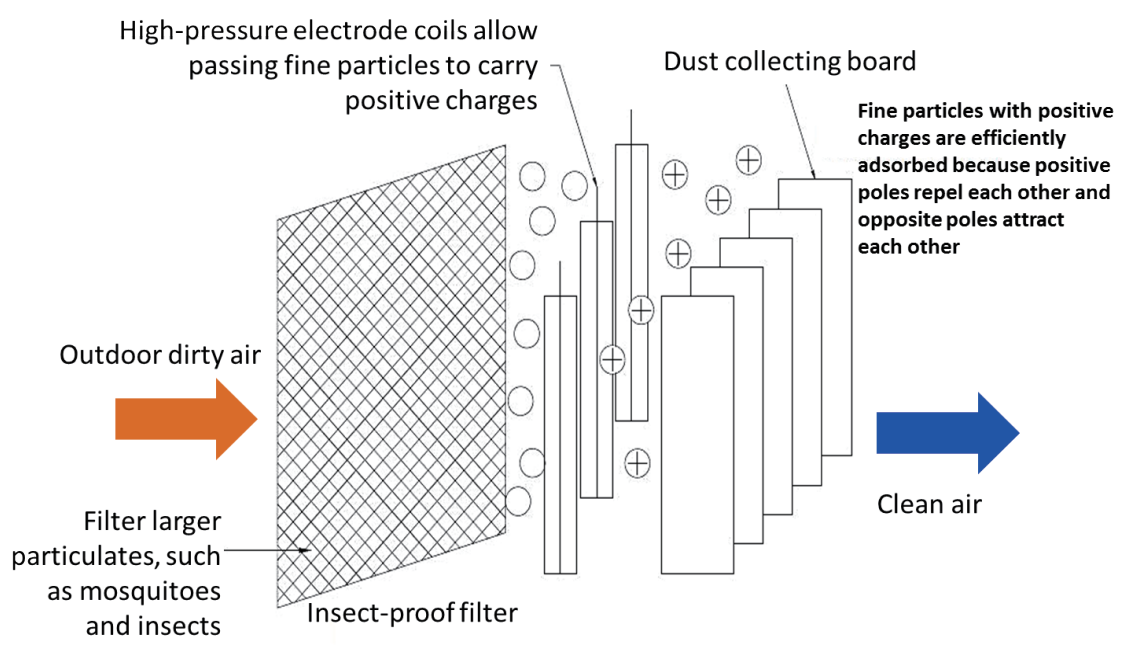

Fig. 13. (Color online) Working principle of VADCD (I).

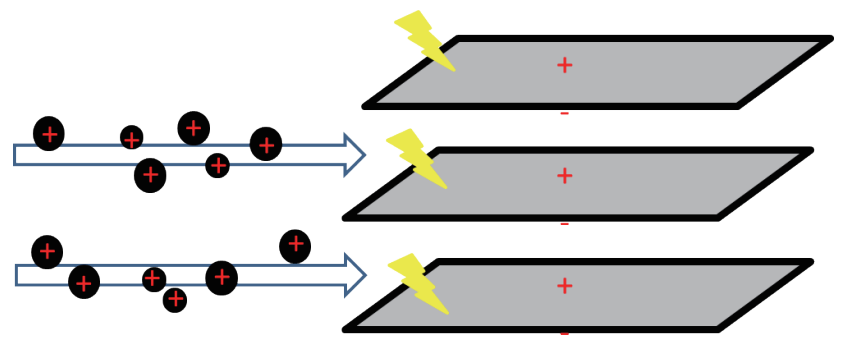

Fig. 14. (Color online) Working principle of VADCD (II).

\section{B. Principle of needle discharge}

Needle discharge is one of the corona discharging phenomena. Its principle is that air around the needle of the conductor flows through the high-pressure electric field, and when voltage is sufficiently high, the air flowing around the conductor is ionized. The device adopted in this study used the needle discharge to allow the air to be ionized and carry charges when the air flows through the high-pressure metal wire. By considering the equation of theoretical efficiency of the VADCD, the voltage adsorption device used the Deutsch-Anderson equation as follows.

$$
\eta=1-e^{-\left(\frac{A \times v}{Q}\right)}
$$

$\eta$ : efficiency of dust collection

$Q:$ air volume

$A$ : area of the dust-collecting board

$v$ : velocity of particles with charges to the dust-collecting board 
According to the above equation, $\eta$ is directly proportional to the area of the dust-collecting board, but it is inversely proportional to the amount of wind. Therefore, the adopted VADCD should match the amount of wind of the device used to attain the best effect.

\section{Principle of ERV}

As shown in Fig. 15, the ERV has four air vents in connection, namely, an outdoor inlet for external air, an outdoor outlet for indoor air, an indoor feeding hole for external air, and an indoor outlet. This novel concept for buildings focuses on healthy air and the energy saving effect. The ERV performs the mandatory ventilation by using the motor configured to induce the introduction and discharge of air. Because the core is paper, latent heat and prominent heat can be exchanged while introducing and discharging air. Accordingly, cold or hot air can remain indoors while introducing and discharging air, and this feature prevents the air conditioning system from being overloaded when introducing external air in summer to save energy. A single-phase $220 \mathrm{~V} / 60 \mathrm{~Hz}$ power source is used, the air volume is $150 \mathrm{CMH}$, the power consumption is $145 \mathrm{~W}$, and the efficiencies of temperature exchange and enthalpy exchange in a cold room are 69 and 58\%, respectively.

There are two formulas for calculating the air volume:

A. In accordance with the technical guide for indoor air quality improvement. ${ }^{(25)}$ This formula is expressed as

$$
Q\left(\frac{\mathrm{m}^{3}}{\mathrm{~min}}\right)=\frac{\text { people } \times 0.0002\left(\frac{\mathrm{m}^{3}}{\min \times \text { person }}\right) \times 10^{6}}{C_{1}(\mathrm{ppm})-C_{0}(\mathrm{ppm})},
$$

where $C_{0}$ is the average $\mathrm{CO}_{2}$ concentration of the outdoor area, $C_{1}$ is the ideal $\mathrm{CO}_{2}$ concentration in the room, and $Q$ is the amount of external air required by the room.

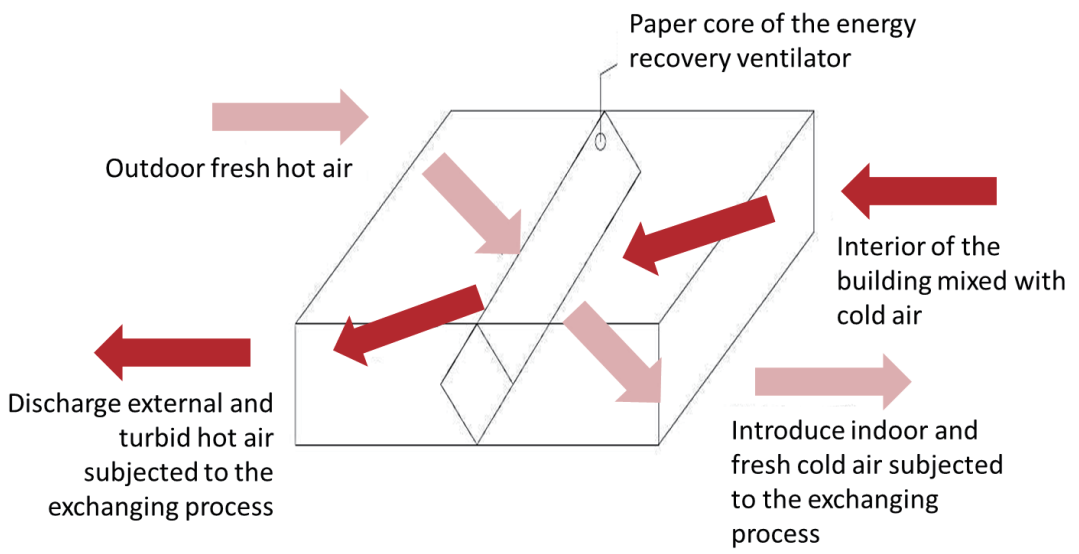

Fig. 15. (Color online) Working principle of ERV. 
B. The formula in ASHRAE S62.1-2010, ${ }^{(3)}$ which is

$$
V_{b z}=\left(R_{p} \times P_{Z}\right)+\left(R_{A} \times A_{Z}\right),
$$

where $V_{b z}$ is the required air volume, $R_{p}$ is the required amount of outdoor air (CMM/person), $P_{Z}$ is the number of persons, and $R_{A}$ is the required amount of outdoor air per unit area $\left(\mathrm{CMM} / \mathrm{m}^{2}\right)$ and $A_{Z}\left(\mathrm{~m}^{2}\right)$.

In this study, the air volume is calculated in accordance with the indoor air quality improvement manual $^{(26)}$ as

$$
Q=\frac{6(\text { people }) \times 0.0002 \frac{\mathrm{m}^{3}}{\min \times \text { person }} \times 10^{6}}{1000(\mathrm{ppm})-500(\mathrm{ppm})}=2.4 C M M\left(\frac{\mathrm{m}^{3}}{\mathrm{~min}}\right)=144 C M H\left(\frac{\mathrm{m}^{3}}{\mathrm{~h}}\right) \approx 150 C M H\left(\frac{\mathrm{m}^{3}}{\mathrm{~h}}\right)
$$

where $150 \mathrm{CMH}$ is selected as the amount of wind passing through the ERV.

The formulas used to calculate the ventilation frequency in the space are as follows:

A. Air volume/volume of space $=$ frequency of ventilation (number of air changes $/ \mathrm{h}$ ).

B. Ventilation frequency (number of air changes $/ \mathrm{h}$ ) $=150 \mathrm{CMH} / 211.9 \mathrm{~m}^{3}$ (without deductions for volume of furnishings) $=0.7$ time per hour $\approx 1.0$ time per hour.

\subsection{Measurement apparatus and their specifications}

A. Name of apparatus: multipoint gas analyzer (iAeris 14)

The iAeris 14 apparatus measures and records the following factors: $\mathrm{CO}_{2}, \mathrm{CO}$, TVOCs, $\mathrm{HCHO}, \mathrm{PM}_{2.5}, \mathrm{PM}_{10}$, dry bulb temperature, and relative humidity. This measurement apparatus also has six-pollution source range specifications, as shown in Table 2.

B. Name of apparatus: multifunction ventilation meter with differential pressure sensor (TSI 9565-P)

The TSI 9565-P apparatus uses a hot wire sensor type and measures and records the following factors: velocity for probe, velocity for Pitot tube, differential pressure, dry bulb temperature, wet bulb temperature, operating temperature, and relative humidity. This measurement apparatus also has seven-item range specifications, as shown in Table 3.

Table 2

Basic specifications of iAeris 14 apparatus.

\begin{tabular}{lcc}
\hline Factor & Monitoring scope & Resolution \\
\hline Dry bulb temperature & $-40-+125^{\circ} \mathrm{C}$ & $\pm 0.1{ }^{\circ} \mathrm{C}$ \\
Relative humidity & $0-100 \% \mathrm{RH}$ & $\pm 1 \% \mathrm{RH}$ \\
$\mathrm{CO}_{2}$ & $400-5000 \mathrm{ppm}$ & $\pm 1 \mathrm{ppm}$ \\
$\mathrm{CO}$ & $0-1000 \mathrm{ppm}$ & $\pm 1 \mathrm{ppm}$ \\
$\mathrm{PM}_{2.5} / \mathrm{PM}_{10}$ & $0-500 \mu \mathrm{g} / \mathrm{m}^{3}$ & $\pm 1 \mu \mathrm{g} / \mathrm{m}^{3}$ \\
$\mathrm{TVOCs}$ & $0.13-2.5 \mathrm{ppm}$ & $\pm 0.01 \mathrm{ppm}$ \\
$\mathrm{HCHO}$ & $0.00-5.00 \mathrm{ppm}$ & $\pm 0.01 \mathrm{ppm}$ \\
\hline
\end{tabular}


Table 3

Basic specifications of TSI 9565-P apparatus.

\begin{tabular}{lcc}
\hline Factor & Monitoring scope & Resolution \\
\hline Velocity for probe & $0.0-50.0 \mathrm{~m} / \mathrm{s}$ & $\pm 0.01 \mathrm{~m} / \mathrm{s}$ \\
Velocity for Pitot tube & $1.27-78.7 \mathrm{~m} / \mathrm{s}$ & $\pm 0.01 \mathrm{~m} / \mathrm{s}$ \\
Differential pressure & $-3735-+3735 \mathrm{~Pa}$ & $\pm 0.1 \mathrm{~Pa}$ \\
Dry bulb temperature & $-10-+60{ }^{\circ} \mathrm{C}$ & $\pm 0.1{ }^{\circ} \mathrm{C}$ \\
Operating temperature & $-10-+60{ }^{\circ} \mathrm{C}$ & $\pm 0.1{ }^{\circ} \mathrm{C}$ \\
Wet bulb temperature & $5-60{ }^{\circ} \mathrm{C}$ & $\pm 0.1{ }^{\circ} \mathrm{C}$ \\
Relative humidity & $5-95 \%$ & $\pm 0.1 \%$ \\
\hline
\end{tabular}

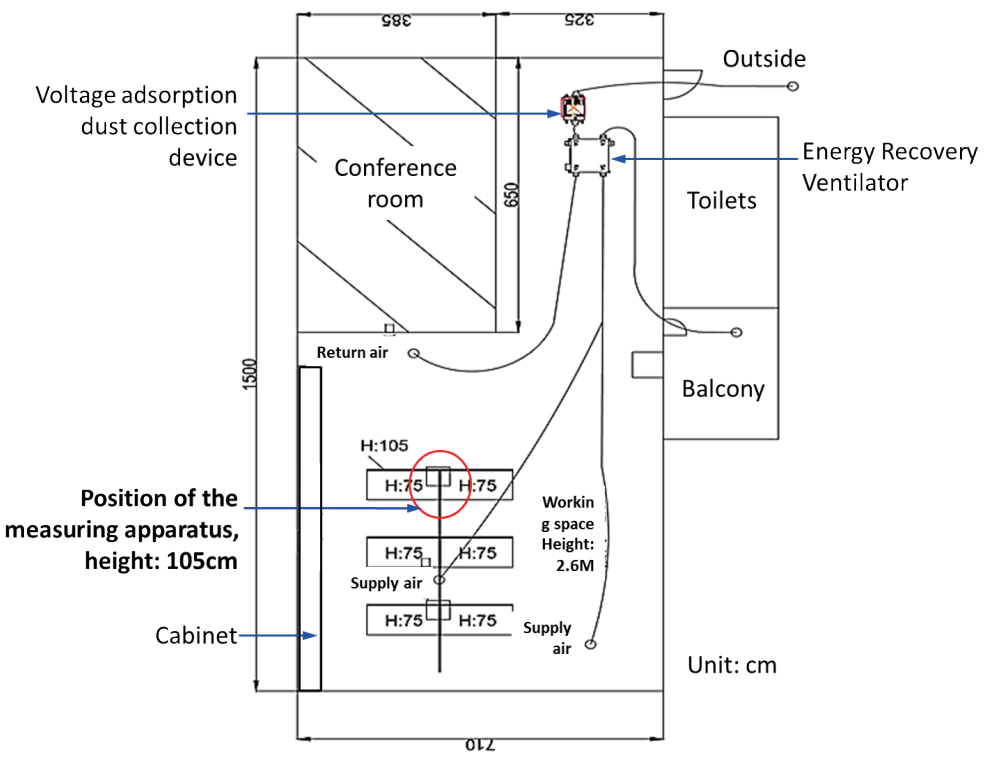

Fig. 16. (Color online) Plan of indoor measurement area. ${ }^{(26)}$

\subsection{Experimental area}

The experimental area is a working place with an area of $81.5 \mathrm{~m}^{2}$ and a height of $260 \mathrm{~cm}$. As shown in Fig. 16, there are six seats in the office, where outdoor air is introduced to pass through the VADCD and then to the ERV, before finally entering the indoor space.

\section{Results and Discussion: Experimental Data}

\subsection{Concentrations of pollutants when both the ERV and the VADCD are in operation}

The experimental apparatus start time to operate the ERV and VADCD is between 09:00 AM and 18:00 PM from the first day to the seventh day per week. As shown in Fig. 17, the maximum concentration of indoor $\mathrm{CO}_{2}$ is $1200 \mathrm{ppm}$, and most of the concentrations obtained are lower than $1000 \mathrm{ppm}$ when both the ERV and the VADCD are in operation. The measured concentrations on the second day and fourth day exceeded the recommended concentration 


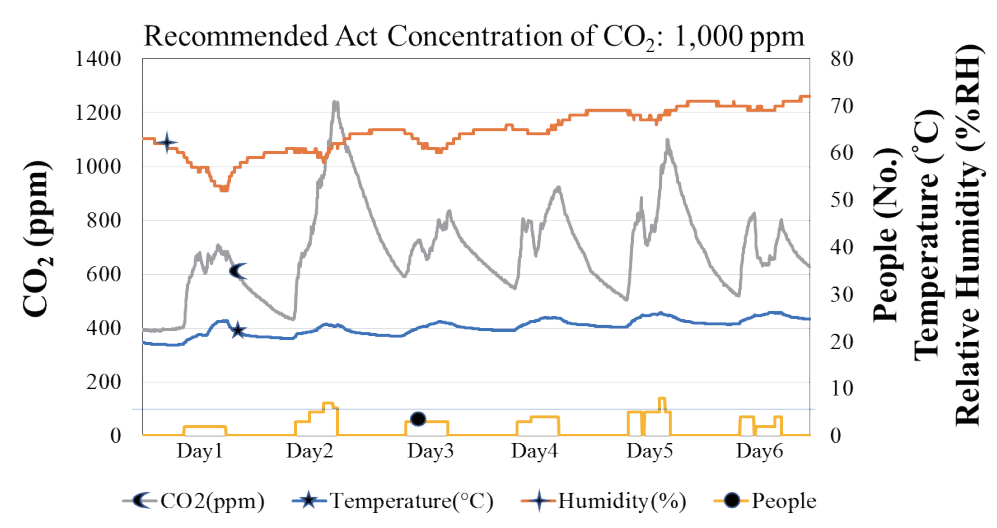

Fig. 17. (Color online) Measured $\mathrm{CO}_{2}$ concentration, number of persons, temperature, and relative humidity.

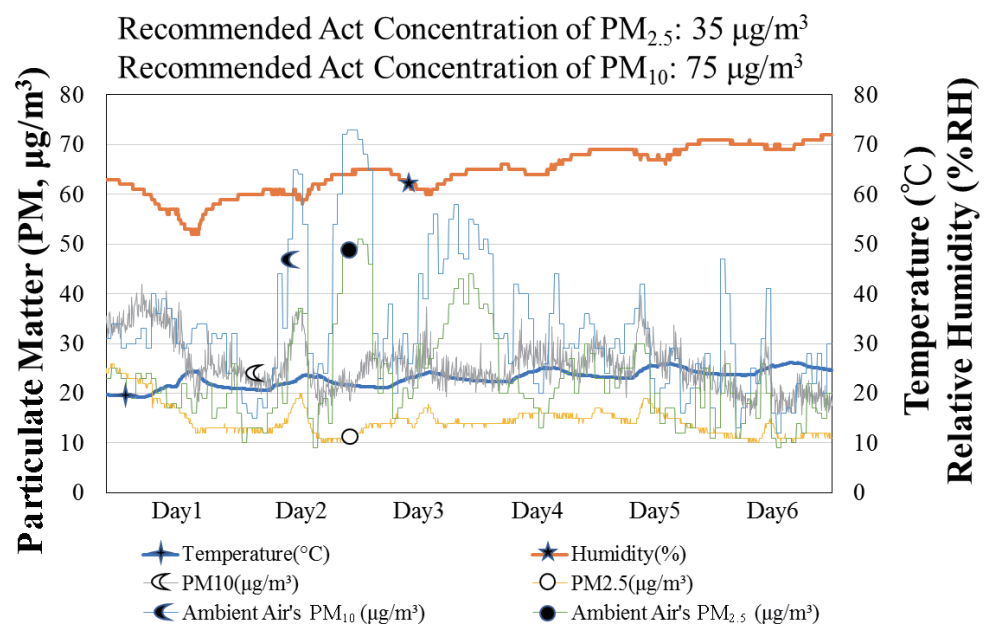

Fig. 18. (Color online) Measured indoor $\mathrm{PM}_{2.5} / \mathrm{PM}_{10}$, outdoor $\mathrm{PM}_{2.5} / \mathrm{PM}_{10}$, temperature, and relative humidity.

because a sudden increase in the number of persons rendered the supply of fresh air unable to meet the demand.

As shown in Fig. 18, the concentrations of indoor $\mathrm{PM}_{2.5}$ and indoor $\mathrm{PM}_{10}$ are both lower than the recommended maxima when both the ERV and the VADCD are in operation. However, external air still affected the curved graph of indoor $\mathrm{PM}_{2.5}$ and indoor $\mathrm{PM}_{10}$, but the impact was only small. It can be inferred that because the filtering operation of the VADCD executed once had a limited filtering effect, a few particulates still entered the office, and this entry caused the indoor concentration to be slightly affected by the outdoor concentration.

As shown in Fig. 19, the concentration of HCHO is clearly reduced when both the ERV and the VADCD are operated on day 1 and day 2. However, it subsequently increases again when there is no ventilation or both the ERV and the VADCD are instantaneously not operated from day 2 to day 6, but it is still below $0.08 \mathrm{ppm}$. Accordingly, it can be inferred that the ventilation 
can improve the dilution diffusion of $\mathrm{HCHO}$, which is made on the premise that the long-term and continuous ventilation is required.

As shown in Fig. 20, the CO concentration in this office is measured but found that the concentration is zero when both the ERV and the VADCD are operated. This is because no activities whereby $\mathrm{CO}$ is produced are carried out in the office and the outdoor $\mathrm{CO}$ concentration is not measured.

As shown in Fig. 21, the TVOC concentration markedly decreases when both the ERV and the VADCD are operated during the day. However, at night after the working time, the TVOC concentration increases again when both the ERV and the VADCD are closed. However, the concentration gradually decreases when the equipment is operated during the day. Although the TVOC concentrations measured in this office are far lower than the recommended concentration (below $0.56 \mathrm{ppm}$ ), increasing the ventilation can further reduce the indoor TVOC concentration.

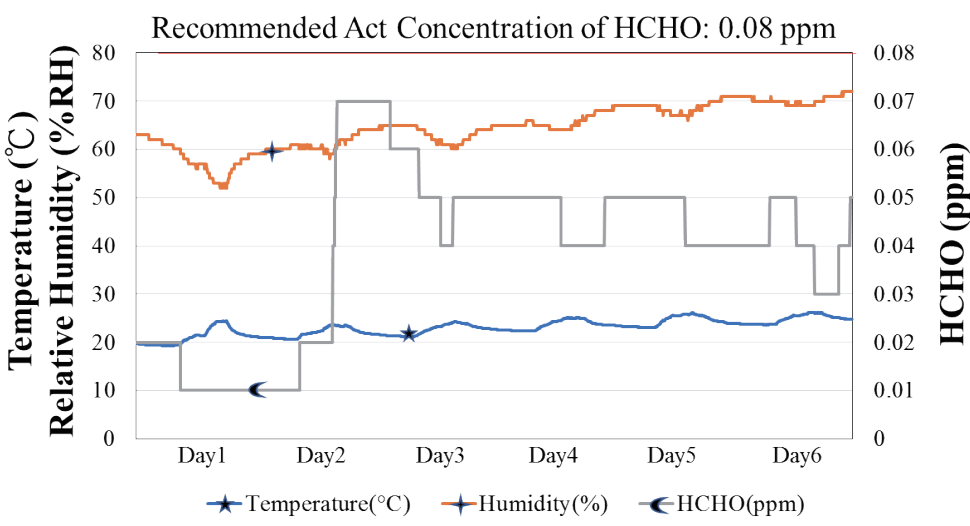

Fig. 19. (Color online) Measured HCHO, temperature, and relative humidity.

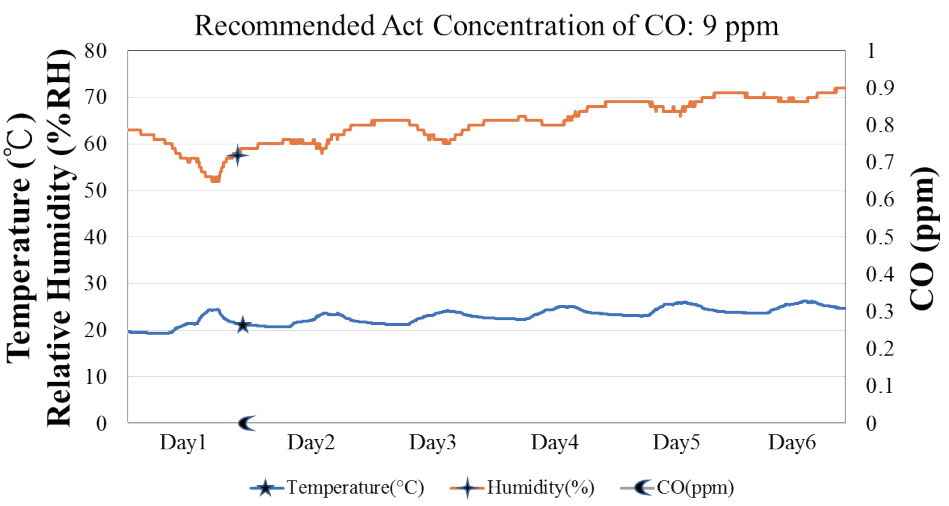

Fig. 20. (Color online) Measured CO, temperature, and relative humidity. 


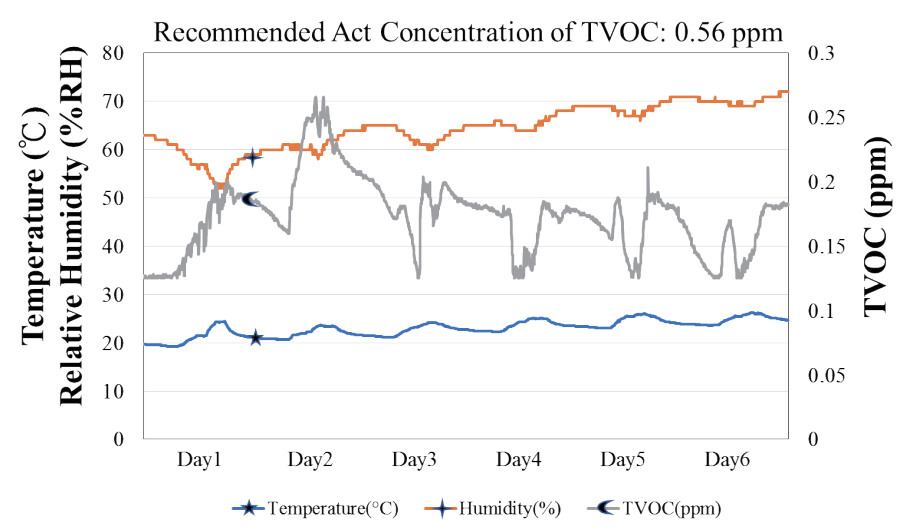

Fig. 21. (Color online) Measured relationships between TVOC concentration, temperature, and relative humidity.

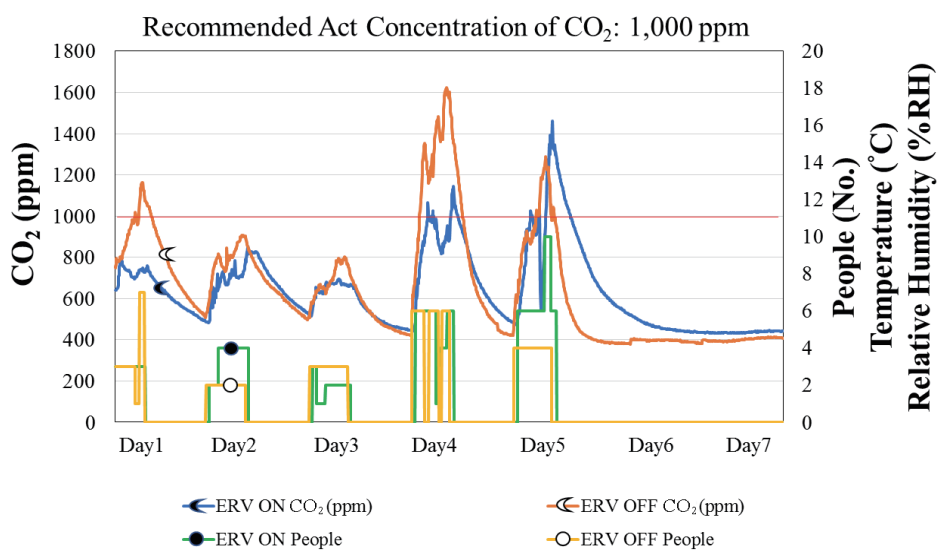

Fig. 22. (Color online) Comparison of indoor $\mathrm{CO}_{2}$ concentrations measured with and without operating the ERV.

\subsection{Results and comprehensive analysis of measured data}

As shown in Fig. 22, if the volume of air adopted by the ERV is very low, there will be an insufficient number of air changes. This causes the $\mathrm{CO}_{2}$ concentration to increase to $1500 \mathrm{ppm}$ when the number of persons suddenly increases on the fifth day and the frequency of ventilation is insufficient. Accordingly, to reduce the $\mathrm{CO}_{2}$ concentration by using the ERV within an office, a sudden increase in the number of persons should be taken into account.

As shown in Fig. 23, the average concentration of $\mathrm{PM}_{2.5}$ measured with operating the VADCD is lower than that measured without operating the VADCD. Therefore, the cooperation between the VADCD and the ERV can further reduce the average $\mathrm{PM}_{2.5}$ concentration. The $\mathrm{PM}_{2.5}$ introduced from outside to inside via the ERV can be filtered, and concurrently, the indoor $\mathrm{PM}_{2.5}$ can be removed to reduce the $\mathrm{PM}_{2.5}$ concentration inside the office and attain higher air quality. 


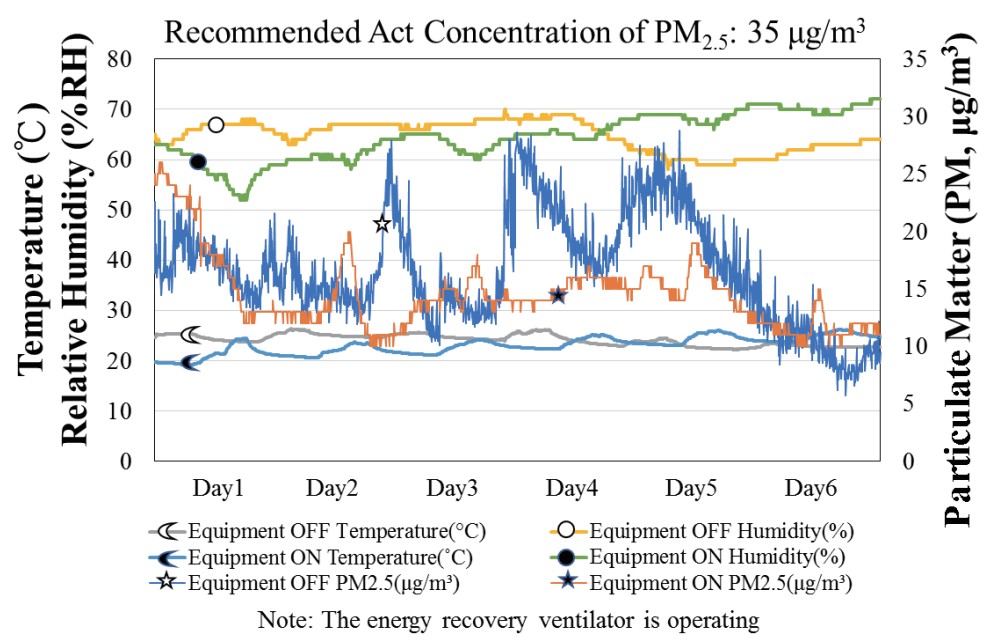

Fig. 23. (Color online) Comparison of indoor $\mathrm{PM}_{2.5}$ concentrations measured with and without operating the VADCD.

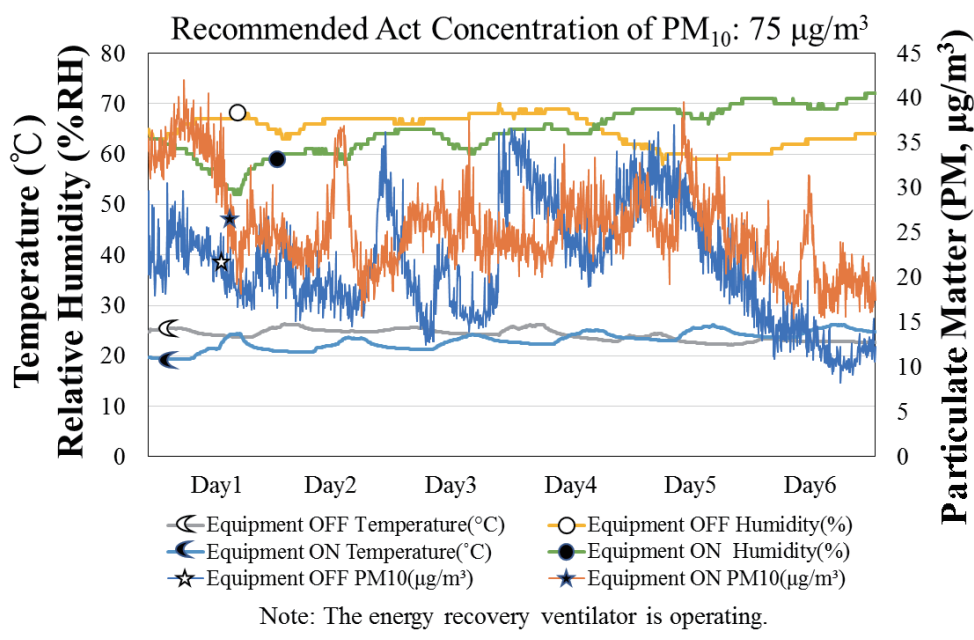

Fig. 24. (Color online) Comparison of indoor $\mathrm{PM}_{10}$ concentrations measured with and without operating the VADCD.

As shown in Fig. 24, the average $\mathrm{PM}_{10}$ concentration measured with operating the VADCD approaches that measured without operating the VADCD. Because the VADCD operates with the ERV introduction of external air, the VADCD can filter some $\mathrm{PM}_{10}$ and stably reduce the number of indoor $\mathrm{PM}_{10}$ pollution sources. The VADCD can be started immediately, which can effectively lower the indoor $\mathrm{PM}_{10}$ concentration to less than that stipulated in the Indoor Air Quality Management Act, ${ }^{(1)}$ when the ERV is operating and with the introduction of outdoor air indoors, which may generate some suspended particles or dust.

As shown in Fig. 25, the operation of the ERV does not have a strong effect on the CO concentration in the office. No activities produce $\mathrm{CO}$ in the office and no $\mathrm{CO}$ exists outside, so the reduction in $\mathrm{CO}$ concentration in the indoor office cannot be discussed. 
As shown in Fig. 26, the average indoor $\mathrm{HCHO}$ concentration measured with operating the ERV is lower than that measured without operating the ERV, but the reduction in the concentration is not significant. The concentrations measured during the working days, that is, day 1 to day 5, are higher than those measured on day 6 and day 7. Accordingly, it can be inferred that the $\mathrm{HCHO}$ concentration might increase as a result of not only painted furnishings but also accessories of people, such as leather goods, wooden cabinet, tables, and chairs. Therefore, long-term and effective ventilation can protect people from exposure to $\mathrm{HCHO}$.

Figure 27 shows the effect of the on/off operation of the ERV on the TVOC concentration. The indoor TVOC concentration has an average of $0.2 \mathrm{ppm}$ when the ERV is out of operation, compared with $0.15 \mathrm{ppm}$ when the ERV is in operation. However, when the ERV is off on day 6, the TVOC concentration increases again to $0.3 \mathrm{ppm}$. Accordingly, the ERV should be in longterm continuous use to maintain a low TVOC concentration.

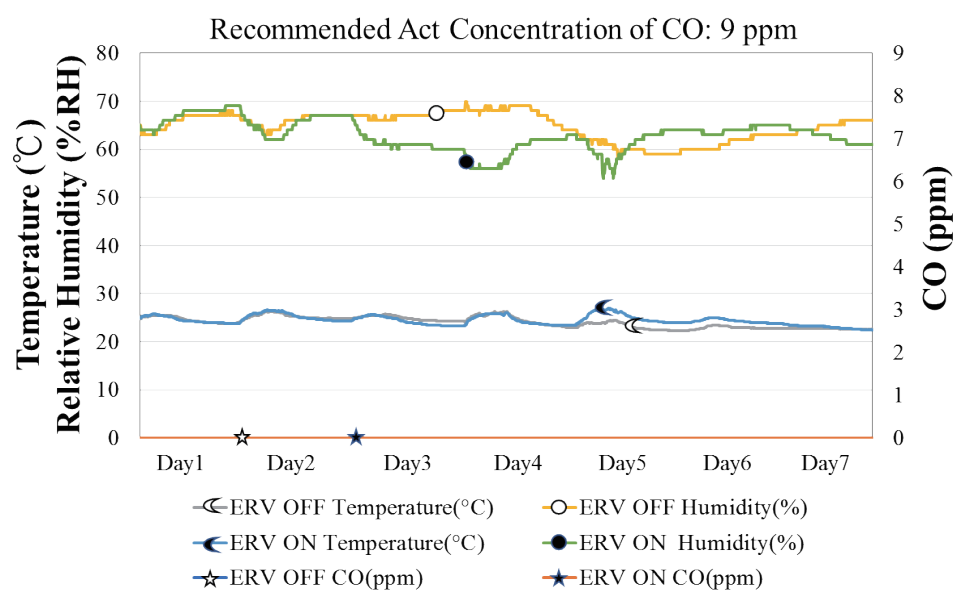

Fig. 25. (Color online) Comparison of indoor CO concentrations measured with and without operating the ERV.

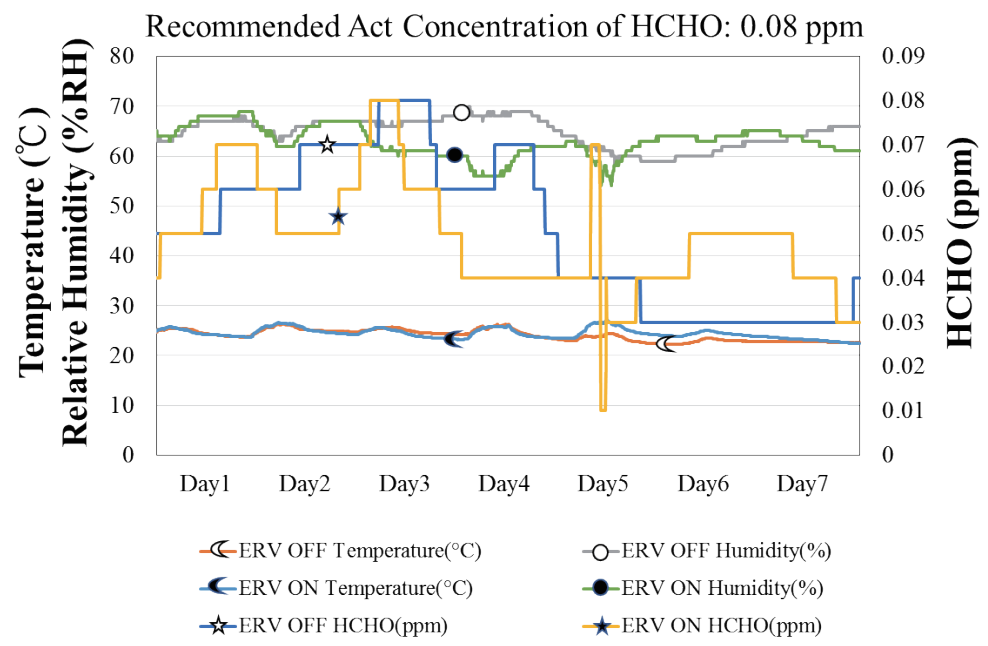

Fig. 26. (Color online) Comparison of indoor HCHO concentrations measured with and without operating the ERV. 


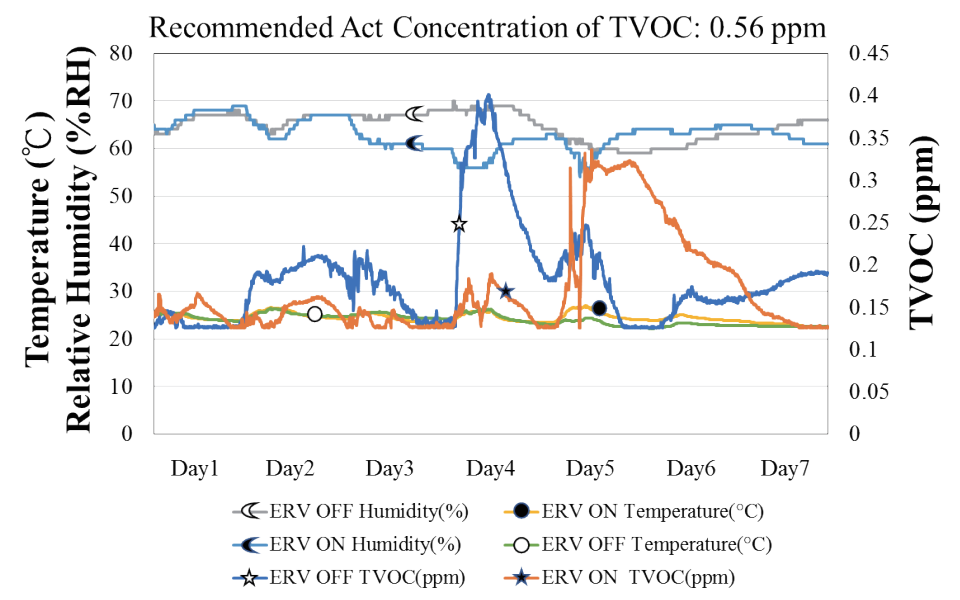

Fig. 27. (Color online) Comparison of indoor TVOC concentrations measured with and without operating the ERV.

\section{Conclusions}

From actual measurements and CFD, we showed the improvement in the distributions of $\mathrm{CO}_{2}, \mathrm{PM}_{2.5}$, and $\mathrm{PM}_{10}$ inside a space in a commercial building, and observed that different effects are caused by the same air vent and wind velocity as a result of different properties of the pollutants. The $\mathrm{CO}_{2}$ concentration in an outdoor environment is inevitably lower than that in the indoor environment, and there is little variation observed among the outdoor values. Therefore, the timely introduction of external air can improve the air quality in an office. The indoor $\mathrm{PM}_{2.5}$ concentration in the office is about $25 \mu \mathrm{g} / \mathrm{m}^{3}$ and that of the indoor $\mathrm{PM}_{10}$ is about $35 \mu \mathrm{g} / \mathrm{m}^{3}$. The outdoor concentrations of these particulates vary to a great extent according to the weather and wind directions. After external particulates are introduced into an office, they accumulate at the corners and are difficult to remove. To improve the air quality in an office, the effect of the external environment on the indoor environment should be taken into account, or the introduction of external pollutants into the indoor environment should be prevented.

The diffusion of $\mathrm{CO}_{2}$ was observed to be high even after changing the positions of the air vents in the simulation, thus reducing its concentration in the working area by $5 \%$, whereas the concentration increased in the walkway. Accordingly, it is suggested that if space and time permit, air vents should be placed on the ceiling above the working area of the staff. We found that the positions of the air vents affected the areas where the indoor particulates spread and accumulated, but a filtering process reduced the $\mathrm{PM}_{2.5} / \mathrm{PM}_{10}$ concentrations, particularly around the working area of the staff. If it is not possible to open windows to ventilate an office space, one approach to improve the indoor air quality is to install an ERV. However, if the ERV is operated without the simultaneous use of a device capable of filtering particulates, outdoor particulates will be introduced, increasing the indoor concentration of particulates to approach the outdoor concentration of particulates. The cooperation between the ERV and the VADCD can improve the overall indoor air quality. However, it is suggested that the number of persons in the area and the filtering of external particulates should additionally be taken into account for 
higher indoor air quality when using external air devices in the office to improve the indoor air quality. We recommend that the air volume is adopted by the mandatory ventilation device and calculated by totaling the air volume of the ERV and considering the number of persons $\times 30$ $\mathrm{CMH} \times 120 \%$. This can solve the problems of indoor air quality and suspended particles when both the ERV and the VADCD are operated.

\section{Acknowledgments}

The authors would like to thank TORNEX Inc. and their CEO Shih-Ping Lu for their willingness to support this research.

\section{References}

1 Laws and Regulations Retrieving System: Indoor Air Quality Act. Environmental Protection Administration. Executive Yuan. R.O.C. (Taiwan), https://oaout.epa.gov.tw/law (accessed February 2020).

2 ASHRAE - ANSI/ASHRAE Standard 62.1-2013 - Ventilation for Acceptable Indoor Air Quality. ISSN 10412336, http://www.myiaire.com/product-docs/ultraDRY/ASHRAE62.1.pdf (accessed November 2019).

3 ASHRAE-ANSI/ASHRAE Standard 62.1-2010 - Ventilation for Acceptable Indoor Air Quality, ISSN 10412336, http://arco-hvac.ir/wp-content/uploads/2016/04/ASHRAE-62_1-2010.pdf (accessed November 2019).

4 Laws and Regulations Retrieving System: Management Regulations for Indoor Air Quality Inspection. Environmental Protection Administration. Executive Yuan. R.O.C. (Taiwan), https://oaout.epa.gov.tw/law (accessed February 2020).

5 National Health Commission - Hygienic Indicators and Limits for Public Places, National Standard People's Republic of China, GB 37488-2019, https://www.chinesestandard.net/PDF/English.aspx/GB37488-2019 (accessed December 2019).

6 Ministry of the Environment of Singapore: Guidelines for Good Indoor Air Quality in Office Premises, 1st ed., Institute of Environmental Epidemiology, https:/www.bca.gov.sg/greenmark/others/NEA_Office_IAQ_ Guidelines.pdf (accessed October 2019).

7 Korean Society of Indoor Environment: http://www.kosie.or.kr/english/intro_01.html (accessed March 2020).

8 Indoor Air Quality Management Team Group, Environmental Protection Department of Hong Kong: Indoor Air Quality Certification Scheme for Offices and Public Places Guide, https://www.iaq.gov.hk/media/65349/ new-iaq-guide_chi.pdf (accessed September 2019).

9 Society of Indoor Environment of Japan: http://www.siej.org/english/intoro.html (accessed January 2020).

10 Ministry of Health, Labour and Welfare of Japan: Building environmental hygiene management standard, https://www.mhlw.go.jp/english (accessed January 2020).

11 Environmental Protection Administration, Environmental Protection Administration, Executive Yuan. R.O.C. (Taiwan): Taiwan Air Quality Monitoring Network, https://airtw.epa.gov.tw/CHT/default.aspx (accessed June 2020).

12 Carbon Dioxide Concentration Standard: How Many ppm is Harmful to Human Body? https://www.sohu.com/ a/288858682_472588 (accessed January 2020).

13 C. C. Yang: Taiwan Clin. Oncol. Res. Found. 54 (2011) 1. http://web.tccf.org.tw/lifetype/index. php?op=ViewArticle\&articleId=2832\&blogId=1 (accessed May 2020).

14 World Health Organization: Air Pollution for Indoor Air Quality, https://www.who.int (accessed July 2020).

15 Dept. Air Quality Protection and Noise Control. Environmental Protection Administration. Executive Yuan. R.O.C. (Taiwan): Environmental Protection Administration Announced $\mathrm{PM}_{2.5}$ Emissions from Various Sources in Taiwan, https://enews.epa.gov.tw/Page/3B3C62C78849F32F/fala71a5-ea8c-4f84-8bebe0a80d1183eb (accessed April 2020).

16 H. J. Choi: Ph.D. Dissertation (Walden University, Minneapolis, Minnesota, 2018).

17 Y. K. Shou, Y. L. Huang, X. Z. Zhu, C. Q. Liu, Y. Hu, and H. H. Wang: Ecotoxicol. Environ. Safety 174 (2019) 344. https://doi.org/10.1016/j.ecoenv.2019.02.086.

18 W. H. Yue, L. Tong, X. H. Liu, X. Y. Weng, X. Y. Chen, D. Z. Wang, S. C. Dudley, E. K. Weir, W. J. Ding, Z. B. Lu, Y. W. Xu, and Y. J. Chen: Redox Biol. 22 (2019) 101161. https://doi: 10.1016/j.redox.2019.101161 
19 Home Well Web (ARTIIX-Jimmy): Sources and Harmfulness of Total Volatile Organic Compounds (TVOC), https://janshiun.pixnet.net/blog/post (accessed April 2020).

20 I. C. Lin: M.S. Thesis, Dept. Energy and Refrigerating Air-Conditioning Eng. (NTUT, Taipei, Taiwan, 2018).

21 T. C. Le: M.S. Thesis, Inst. Environmental Eng. (NCTU, Hsinchu, Taiwan, 2013).

22 C. L. Lai: M.S. Thesis, Dept. Mech. Eng. (NTUST, Taipei, Taiwan, 2019).

23 S. V. Patankar and D. B. Spalding: Int. J. Heat Mass Transfer. 15 (1972) 1787. https://doi.org/10.1016/00179310(72)90054-3.

24 S. V. Patankar: Numerical Heat Transfer and Fluid Flow, W. J. Minkowycz and E. M. Sparrow, Eds. (Taylor \& Francis, London, 1980) 1st ed., Chap. 6.

25 Industrial Safety and Health Association of the Republic of China: Evaluation and Calculation of Indoor Ventilation Volume and Improvement of Air Conditioning and Ventilation System-Technical Manual of Indoor Air Quality Improvement (Taipei, Taiwan, 2016)

26 TORNEX Inc.: Commercial Office, Equipment, Space, Testing, and Area (Taipei, Taiwan, 2019-2020).

\section{About the Authors}

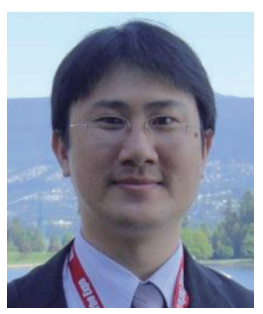

Chih-Neng Hsu received his M.S. and Ph.D. degrees from National Tsing Hua University, Taiwan, R.O.C., in 2000 and 2005, respectively. From 2011 to 2015, he was an assistant professor at National Chin-Yi University of Technology, Taiwan, R.O.C. Since 2015, he has been an associate professor at National Chin-Yi University of Technology. His research interests are in refrigeration, air conditioning, LEDs/laser diodes, thermal fluid science, energy engineering, lighting, electronic cooling, $\mathrm{CFD} / \mathrm{CAD} / \mathrm{CAE}$, measurement, IAQ, energy saving, and graphene materials.

(cnhsu@ncut.edu.tw)

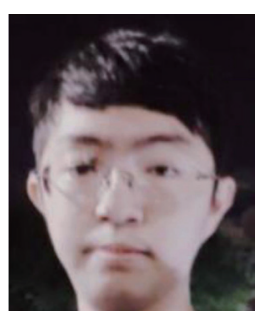

Yun-Lin Tsai received his B.S. and M.S. degrees from National ChinYi University of Technology, Taiwan, in 2017 and 2020, respectively. His research interests are in refrigeration, air conditioning, IAQ, CFD/CAD, measurement, and thermal fluids. (p900044@yahoo.com.tw) 